\title{
Clinical Profile of Adverse Cutaenous Drug Reactions in Patients with Human Immunodeficiency Virus
}

\author{
Puteri Nabilah Maharani, ${ }^{1}$ Oki Suwarsa, ${ }^{2}$ Susantina ${ }^{3}$ \\ ${ }^{1}$ Faculty of Medicine Universitas Padjadjaran, Indonesia, ${ }^{2}$ Department of Dermatology \& \\ Venereology Faculty of Medicine Universitas Padjadjaran/Dr. Hasan Sadikin General Hospital \\ Bandung Indonesia, ${ }^{3}$ Department of Internal Medicine Faculty of Medicine Universitas \\ Padjadjaran/Dr. Hasan Sadikin General Hospital Bandung, Indonesia
}

\begin{abstract}
Background: Adverse cutaneous drug reactions (ACDRs) are common problems in patients during the treatment of various diseases. The clinical feature varies from mild manifestation such as morbilliform, urticaria, and contact dermatitis, to severe manifestation such as Stevens-Johnson syndrome (SJS) and Toxic Epidermal Necrolysis (TEN). Patients infected with the human immunodeficiency virus (HIV) have an increased risk of developing ACDRs due to immune system disruption. This study aimed to describe the clinical features of ACDRs in HIV patients and the drugs that cause ACDRs.

Methods: This study was a retrospective study using secondary data from medical records of HIV patients with ACDRs who visited Teratai Clinic of Dr. Hasan Sadikin General Hospital Bandung from 2014 to 2018. Total sampling was applied and results were presented in percentage.

Results: There were 94 HIV patients with ACDRs out of 557 HIV patients. Adverse cutaneous drug reactions are commonly found in males aged 20-39 years old. The clinical features found were morbilliform (85.6\%), SJS (8.9\%), urticaria (4.4\%), and erythroderma (1.1\%). The most common drugs causing ACDRs were Cotrimoxazole (30\%), Efavirenz (28.9\%), and Nevirapine (16.7\%).

Conclusions: The prevalence of ACDRs in HIV patients in this study is $16.9 \%$. The most common clinical features are morbilli form and SJS with Cotrimoxazole, Efavirenz, and Nevirapine causing most of the ACDRs.
\end{abstract}

Keywords: Adverse cutaneous drug reactions, antiretroviral, drug hypersensitivity

\section{Introduction}

Human immunodeficiency virus (HIV) has been known as a pandemic disease since its first discovery. At the end of 2017, there were 36.9 million individuals infected by HIV globally. Among them, 1.8 million cases were a new infections. It also found that there were 940.000 cases of acquired immune deficiency syndrome (AIDS)-related death. ${ }^{1}$ In Indonesia ${ }^{1}$, there is an increase in a number of people living with HIV (PLHIV) and the number of AIDS-related death cases. The number of PLHIV increased from 610.000 in 2015 to 630.000 in 2017. The number of AIDS-related death is also increased from 37.000 in 2015 and 39.000 in $2017 .{ }^{1}$
HIV targets on a cluster of differentiation 4 (CD4) cells (T helper cells) of its host. This leads to progressive deterioration of hosts' immune systems and causes immunodeficiency in HIVinfected patients. The HIV-infected patients could progress into AIDS. This phase is identified when the CD4 count has reached $<200 / \mu$ l or when the individual develops one or more opportunistic infections. ${ }^{2}$ HIV is treated with highly active antiretroviral therapy (HAART) which is a combination of antiretroviral (ARV). ${ }^{3}$ Opportunistic infections (OIs) are an infection that emerges due to a weakened immune systems and are often found in HIV patients. In HIV-infected patients, OIs could be life-threatening and are the major cause of AIDS-related death. ${ }^{2}$ Patients

Correspondence: Puteri Nabilah Maharani, Faculty of Medicine Universitas Padjadjaran, Jalan Raya Bandung Sumedang Km. 21 Jatinangor, Sumedang, Indonesia, E-mail: nabilahpm@gmail.com 
with AIDS are required to take OIs drugs and ARV. The use of several medications and dysregulation of the immune system could induce adverse drug reactions and drug interactions. ${ }^{4,5}$

Adverse cutaneous drug reactions (ACDRs) are rash found in a layer of skin and mucosa that emerges due to hypersensitivity reaction towards drugs. Drug eruption rates varied from $0-8 \%$ and were found to be a common problem for inpatients globally. ${ }^{6}$ The clinical features vary such as morbilliform, urticaria, contact dermatitis, Stevens-Johnson syndrome (SJS), toxic epidermal necrolysis (TEN), etc. ACDRs were found to be the most common form of adverse drug reaction in HIV patients. It was reported that drug hypersensitivity occurs a hundred times more frequent in HIV patients compared to HIV-negative individuals. ${ }^{7}$ Stevens-Johnson syndrome is a severe and rare skin disorder characterized by painful blister lesions that widespread on the skin and mucous membranes. Incidence of SJS has been linked to the deterioration of the immune system found in HIV infection. ${ }^{7}$ These manifestation could affect patients' adherence and outcomes to therapy, which eventually affect morbidity and mortality rate in HIV patients. This study aimed to describe the local prevalence, patients' characteristics such as sex, age, and CD4 count also clinical features and drug causing ACDRs.

\section{Methods}

This study was conducted from SeptemberNovember 2019 in Teratai Clinic Dr. Hasan Sadikin General Hospital Bandung using a retrospective cross-sectional approach as the study design. This study used secondary data, which were patients' medical records as its instrument. The population of this study was HIV/AIDS patients undergoing ARV therapy in Teratai Clinic. Inclusion criteria were medical records of HIV patients diagnosed with ACDRs while undergoing ARV therapy from 2014-2018 in Teratai Clinic. The exclusion criteria were incomplete medical records. The sampling was total sampling. The total number of the case was 94 but only 90 cases were evaluable. The research has been approved by the Research Ethics Committee of the Universitas Padjadjaran (835/UN6.KEP/ EC/2019).

This study was started by collecting data on HIV patients that were diagnosed with ACDRs in Teratai Clinic. The result was presented in percentage.

\section{Results}

This study found 94 cases from 2014-2018 with the prevalence of $16.9 \%$. ACDRs in HIV patients were found to be more prevalent in men $(70 \%)$ compared to women $(30 \%)$. The

Table 1 Characteristics of HIV Patients with ACDRs

\begin{tabular}{lcc}
\hline \multirow{2}{*}{ Characteristics } & \multicolumn{2}{c}{ HIV Patients with ACDRs (n=90) } \\
\cline { 2 - 3 } & $\mathrm{n}$ & $\%$ \\
\hline Age (years old) & 2 & 2.2 \\
$<20$ & 36 & 40 \\
$20-29$ & 35 & 38.9 \\
$30-39$ & 14 & 15.6 \\
$40-49$ & 3 & 3.3 \\
$50-59$ & & \\
Gender & 63 & 70 \\
Male & 27 & 30 \\
Female & & \\
History of Allergy & 6 & 6.7 \\
Yes & 11 & 12.2 \\
No & 73 & 81.1 \\
Unknown & & \\
\hline
\end{tabular}

Note: ACDRs=adverse cutaneous drug reactions 
Table 2 CD4 Count in HIV Patients with Adverse Cutaneous Drug Reactions and with Opportunistic Infection

\begin{tabular}{lcccc}
\hline & \multicolumn{4}{c}{ CD4 Count (cell/mm3) } \\
\cline { 2 - 5 } & $<200$ & $200-499$ & $\geq 500$ & Total \\
\hline Clinical Features & 37 & 38 & 2 & $77(85.6)$ \\
Morbiliform & 6 & 2 & 0 & $8(8.9)$ \\
Stevens-Johnson Syndrome & 1 & 3 & 0 & $4(4.4)$ \\
Urticaria & 1 & 0 & 0 & $1(1.1)$ \\
Erythroderm & $45(50)$ & $43(47.8)$ & $2(2.2)$ & 90 \\
Total & & & & \\
Opportunistic Infections & 9 & 4 & & $13(27)$ \\
Tuberculosis & 17 & 3 & & $20(41.7)$ \\
Candidiasis & 7 & 1 & & $2(16.7)$ \\
Toxoplasmosis & 1 & 1 & $5(10.4)$ \\
Syphilis & 3 & 2 & 48 \\
Others & $37(77)$ & $11(23)$ & \\
Total & & & & \\
\hline
\end{tabular}

Note: CD4= cluster of differentiation 4

cases were commonly found in age between 20-39 years old $(78.9 \%)$. The majority of the patients do not know their allergy status prior to the incident (81.1\%). Only $6.7 \%$ of the patients have been diagnosed with the allergy before.

This study found that the most common clinical features of ACDRs were morbilliform and SJS (85.6\% and $8.9 \%$ respectively). Half number of the patients (50\%) found to be in the AIDS phase. Only 2 patients (2.2\%) have a high number of CD4. Morbilliform was found in a wide range of populations with variable CD4 count. Other clinical features such as SJS, urticaria, and erythroderm primarily were found in individuals with low CD4 count.

Forty-eight patients $(53.3 \%)$ have opportunistic infection. Opportunistic infections found in HIV patients were Candidiasis (41.7\%), Tuberculosis (27\%), Toxoplasmosis $(16.7 \%)$, Syphilis $(4.2 \%)$, and others (8.5\%).

Cotrimoxazole has the highest number of case-related to ACDRs (27.8\%). Efavirenz and Nevirapine were the most common cause of ACDRs found among the ARV group (26.7\% and $14.5 \%$ respectively). Several drugs, consisting of a combination of antituberculosis, antiretroviral, and antibiotic groups, caused thirteen cases (14.5\%).

\section{Discussions}

This study found predominance in males aged between 20-39 years old. The number of male patients is $63(70 \%)$ with an $\mathrm{M} / \mathrm{F}$ sex ratio of 2.33. This observation is similar to several studies in Asia in China ${ }^{4}$ and Korea ${ }^{8}$ as well as a study in another part of Indonesia. ${ }^{9}$ However, other studies show different results, for example, study in Cameroon, Central Africa $^{10}$ found that $82.9 \%$ of HIV patients with drug eruptions were female. Similar to a study in South Africa that shows a high number of female patients. ${ }^{11}$ This difference is assumed to be caused by the demographic. In Indonesia, there was a higher number of male patients in the HIV-infected population. ${ }^{1}$ The relation between ACDRs and sex was assumed to be influenced by several factors such as body fat percentage, hormonal factor, and enzyme activities. ${ }^{12}$

This study found the majority of the patients were between 20-39 years old. This result is similar to previous studies that also showed a majority of the patients were in age between 30-40 years old, which is reproductive age. $4,8,9$ History of allergy was assumed to influence the incidence of ACDRs. A previous study has found there was the higher rate of allergic history in the drug eruption group compared 
Table 3 Clinical Features in HIV Patient with ACDRs

\begin{tabular}{|c|c|c|c|c|c|}
\hline \multirow{2}{*}{ Suspected drugs } & \multicolumn{5}{|c|}{ Clinical features of ACDRs } \\
\hline & Morbilliform & Urticaria & SJS & Erythroderm & Total \\
\hline \multicolumn{6}{|l|}{ NRTI } \\
\hline Zidovudin & $1(1.3)$ & & $1(12.5)$ & & $2(2.2)$ \\
\hline \multicolumn{6}{|l|}{ NNRTI } \\
\hline Nevirapin & $11(14.3)$ & & $2(25)$ & & $13(14.5)$ \\
\hline Efavirenz & $20(26)$ & $4(100)$ & & & $24(26.7)$ \\
\hline Rilpivirine & $1(1.3)$ & & & & $1(1.1)$ \\
\hline Antituberculosis & $3(3.9)$ & & & $1(100)$ & $4(4.4)$ \\
\hline \multicolumn{6}{|l|}{ Antibiotic } \\
\hline Cotrimoxazole & $23(29.8)$ & & $2(25)$ & & $25(27.8)$ \\
\hline Amoxicillin & $1(1.3)$ & & & & $1(1.1)$ \\
\hline Clindamycin & $1(1.3)$ & & & & $1(1.1)$ \\
\hline \multicolumn{6}{|l|}{ Antifungal } \\
\hline Fluconazole & $3(3.9)$ & & $1(12.5)$ & & $4(4.4)$ \\
\hline \multicolumn{6}{|l|}{ Analgesic } \\
\hline Acetaminophen & $2(2.6)$ & & & & $2(2.2)$ \\
\hline Combination & $11(14.3)$ & & $2(25)$ & & $13(14.5)$ \\
\hline Total & 77 & 4 & 8 & 1 & 90 \\
\hline
\end{tabular}

Note: ACDRs=adverse cutaneous drug reactions, NRTI=nucleoside reverse transcriptase inhibitor, NNRTI= Nonnucleoside reverse transcriptase inhibitor, SJS= Stevens- Johnson syndrome

to the control group, indicating a correlation between the two. ${ }^{4}$ Another study has shown there was no substantial correlation between sex and history of allergy to ACDRs in HIV patients. ${ }^{13}$ In this study, only $6.7 \%$ of people have an allergic history. This low number thought to be caused by the high number of patient that does not know their allergy status.

This study found half number of the patients $(50 \%)$ was in the AIDS phase, characterized by low CD 4 count. A study in South Africa revealed that there was a decreased number of CD4 in HIV patients with TEN. ${ }^{14}$ The exact mechanism of SJS and TEN was still not clearly understood. It has been linked to the depletion of skin-protective CD4 regulatory $\mathrm{T}$ cells that have an important role in maintaining the homeostasis of the skin. The loss of regulatory $\mathrm{T}$ cell leads to expansion of CD8 effect or T cell that could injure keratinocyte. The depletion of CD4 cell found in the HIV population thus increase the risk of developing severe ACDRs, such as SJS and TEN. ${ }^{14,15}$ The low number of CD4 also associated with susceptibility to acquiring OIs. ${ }^{8,16}$ In this study, there were $77 \%$ of patients with a low count of CD4 accompanied with
OIs. This is caused by the incapability of the host's immune system to counter pathogens. This condition requires patients to take both ARV and OIs medications simultaneously. This could induce drug interactions that lead to ACDRs. ${ }^{17}$

In this study, there were 48 cases (53.3\%) that accompanied OIs. The most common OIs is candidiasis and tuberculosis $(41.7 \%$ and $27 \%$ respectively), similar to find in Korea,8and in India. ${ }^{16}$ The high number of tuberculosis in this study could also be supported by the high incidence rate of tuberculosis in Indonesia. ${ }^{18}$

In this study, morbilliform and SJS were found to be the most common clinical features of ACDRs $(85.6 \%$ and $8.9 \%$ respectively). A previous study in the same clinic in Teratai Clinic from 2005 until 2014 has shown similar results that morbilliform and SJS as the most common clinical features in ACDRs among HIV patients $\left(89.7 \%\right.$ and $8.7 \%$ respectively). ${ }^{12}$ The previous study also found that $55 \%$ of the cases found within the group with low CD4 count $\left(<200\right.$ cell $\left./ \mathrm{mm}^{3}\right) .{ }^{12}$

In this study, the suspected drugs were predominant in non-nucleoside reverse 
transcriptase inhibitors (NNRTI) drugs and antibiotic drugs. Efavirenz and Nevirapin have the highest number of cases among NNRTI drugs, $26.7 \%$ and $14.5 \%$ respectively. Cotrimoxazole has the highest number as a suspected drug with $27.8 \%$. Similar to the study in Jakarta ${ }^{17}$ Nevirapine is the most common drug to cause ACDRs, as common as $15 \%$ to $32 \%$. Nevirapine has been used as the most common NNRTI drugs due to its cost-effectiveness, but often associated with adverse drug reactions that could affect cutaneous, hepatic, or systemic. ${ }^{19}$ This study found a lower number of cases associated with Nevirapine compared to Efavirenz. This result is assumed to be caused by the lessened use of Nevirapine due to its known inclination with adverse drug reactions. The exact mechanism of Nevirapine causing ACDRs is still not well understood. It is thought to be related to genetic factors, particularly HLA. A study found Nevirapine shares a common binding groove F pocket with HLA-C*04:01 which increased the risk of hypersensitivity reactions when exposed to Nevirapine. ${ }^{19}$

In this study, SJS as a severe form of ACDRs was found to be commonly caused by Cotrimoxazole $(25 \%)$ and Nevirapine $(25 \%)$. Again, similar to findings in Jakarta that the occurrence of Stevens-Johnson syndrome is higher in Nevirapine compared to Efavirenz. ${ }^{17}$ Another study in Canada ${ }^{20}$ revealed that the incidence of SJS and/or TEN was 1-2 per 1000 individuals in HIV patients. The incidence of SJS and/or TEN in HIV patients often linked to the increased risk of hypersensitivity reaction in HIV patients. It was reported that HIV patients are a hundred times more frequent to acquire drug hypersensitivity compared to HIV negative-individuals. ${ }^{7}$

The exact mechanism of increased risk of hypersensitivity reaction in HIV patients is still unclear. It primarily has been linked to dysregulation of the immune system. The continuous injury of HIV-infected cells and depletion of immunoregulatory cells induce immune response and release of cytokine. This leads to immune activation which is associated with increased production of IP10 and MIG, TNF- $\alpha$, IL-6, IFN- $\alpha$, and IL-10. Immune activation also increased levels of IFN-y that induce an increase in drug presentation and leads to an increased risk of developing hypersensitivity reaction. ${ }^{15}$ Other factors such as changes in drug metabolism, oxidative stress, and genetic factors also have been associated. ${ }^{7,17}$

The limitation of this study is that the diagnosis presented on the data was not confirmed with a specific test which could identify the exact drug causing ACDRs.

In conclusion, CDRs are found to be common in HIV patients, with the prevalence of $16.9 \%$. A high number of cases is found in a young adult males with low CD4. The most common clinical features of ACDRs are morbilliform and SJS. The most common drug ACDRs are Cotrimoxazole, Efavirenz, and Nevirapine.

\section{References}

1. UNAIDS. UNAIDS data 2018. Geneva: UNAIDS; 2018. p.376

2. Abbas AK, Lichtman AH, Pillai S. Basic immunology: functions and disorders of the immune system. 5th ed. St. Louis: Elsevier; 2016

3. Kementerian Kesehatan Republik Indonesia. Pedoman nasional tatalaksana klinis infeksi HIV dan terapi antiretroviral pada orang dewasa. Jakarta: Kementerian Kesehatan RI; 2012.

4. Li YY, Jin YM, He LP, Bai JS, Liu J, Yu M, et al. Clinical analysis of HIV/AIDS patients with drug eruption in Yunnan, China. Sci Rep. 2016;6:35938.

5. Hughes CA, Tseng A, Cooper R. Managing drug interactions in HIV-infected adults with comorbid illness. CMAJ. 2015;187(1):36-43.

6. Pandapotan RA, Rengganis I. Approach to Diagnosis and Treatment of Drug Allergy. Jurnal Penyakit Dalam Indonesia. 2017;4(1):45-52.

7. Minhajat R, Djaharuddin I, Halim $\mathrm{R}$, Benyamin AF, Bakri S. Drugs hypersensitivity reaction in patient with human immunodeficiency virus infection. J Allergy Ther. 2017;8(1):1000252.

8. Kim YJ, Woo JH, Kim MJ, Park DW, Song JY, Kim SW, et al. Opportunistic diseases among HIV-infected patients: a multicenter-nationwide Korean HIV/AIDS cohort study, 2006 to 2013. Korean J Intern Med. 2016;31(5):953-60.

9. Dewi ISL, Hidayati AF. Manifestation of skin disorders in HIV \& AIDS patients. Berkala Ilmu Kesehatan Kulit dan Kelamin. 2015;27(2):97-105

10. Kouotou EA, Nansseu JR, Ngono VN, Tatah SA, Bissek ACZ, Ndam ECN, et al. Prevalence and clinical profile of drug eruptions among antiretroviral therapyexposed HIV infected people in Yaoundé, Cameroon. Dermatology Research and Practice. 2017;2017(1):6216193. 
11. Masenyetse LJ, Manda SOM, Mwambi HG. An assessment of adverse drug reactions among HIV positive patients receiving antiretroviral treatment in South Africa. AIDS Res Ther. 2015;12:6.

12. Armeinesya S, Rowawi R, Hamda ME. Manifestations of allergic drug eruption to antiretroviral in HIV/AIDS patients at Teratai Clinic Dr. Hasan Sadikin General Hospital. JSK. 2018;4(1):24-8.

13. Tesiman J, Sundaru H, Karjadi TH, Setiati S. Prevalence and predictors of atopy in HIV/AIDS patients. Jurnal Penyakit Dalam Indonesia. 2016;3(2):93-9.

14. Yang C, Mosam A, Mankahla A, Dlova N, Saavedra A. HIV infection predisposes skin to toxic epidermal necrolysis via depletion of skin-directed CD4+ T cells. J Am Acad Dermatology. 2014;70(6):1096-102.

15. Peter J, Choshi P, Lehloenya RJ. Drug hypersensitivity in HIV infection. Curr Opin Allergy Clin Immunol. 2019;19(4):272-82.

16. Usmani MH, Qureishi R, Patel R, Kumar PM. Clinical spectrum of opportunistic infections in HIV positive patients. J Evol
Med Dent Sci. 2015;4(24):4076-85.

17. Yunihastuti E, Widhani A, Karjadi TH. Drug hypersensitivity in human immunodeficiency virus-infected patient: challenging diagnosis and management. Asia Pac Allergy. 2014;4(1):54-67.

18. Kementerian Kesehatan RI. Current status of integrated community based TB service delivery and the Global Fund work plan to find missing TB cases. Jakarta: Kementerian Kesehatan RI; 2017.

19. Pavlos R, Mckinnon EJ, Ostrov DA, Peters B, Buus S, Koelle D, et al. Shared peptide binding of HLA Class I and II alleles associate with cutaneous nevirapine hypersensitivity and identify novel risk alleles. Sci Rep. 2017;7(1):8653.

20. Mittmann N, Knowles SR, Koo M, Shear $\mathrm{NH}$, Rachlis A, Rourke SB. Incidence of toxic epidermal necrolysis and StevensJohnson Syndrome in an HIV Cohort: an obseravtional, retrospective case series study. Am J Clin Dermatol. 2012;13(1):4954. 